\title{
Effects of Wire Surface Roughness on Wire EDM Characteristics
}

\author{
Akira OKADA*, Toshiyuki YAMAUCHI**, Masayuki HIGASHI*, \\ Masanori NAKAZAWA*, Toshiaki SHIMIZU** and Yoshiyuki UNO*
}

(Received July 2, 2010)

* Okayama University, 3-1-1, Tsushimanaka, Kitaku, Okayama 700-8530, Japan

** Tokusen Kogyo Co., Ltd, 1081, Sumiyoshi-minamiyama, Ono 675-1361, Japan

\begin{abstract}
The purpose of this study is to develop a new type of coated wire electrode for fine wire EDM. Piano wire with a very high tensile strength is coated with an electrically conductive brass layer to achieve high-speed and high-precision wire EDM. In our previous papers, using a thin wire of $50 \mu \mathrm{m}$ diameter, the thickness and quality of the brass coating layer were optimized and the effects of the tensile strength of the piano wire used as the core wire on machining characteristics were discussed. In this paper, the effect of surface roughness of the brass wire electrode was experimentally investigated. As a result, it was found that by using wire with relatively large surface roughness, the machining rate increased because of the high discharge frequency. Also, a more uniform distribution of the discharge location was confirmed by high-speed observation of the working gap during the process. In addition, the electrostatic field in the gap between the wire electrode and workpiece surface was analyzed and the reason for the high machining rate in case of the wire with relatively large surface roughness was discussed from the viewpoint of the distribution of electric intensity distribution on the wire surface.
\end{abstract}

Key words: wire EDM, coated wire, wire surface roughness, discharge distribution, electrostatic analysis

\section{INTRODUCTION}

The demands for fine precision machining have been recently increased with the miniaturization of mechanical or electronic products. For meeting these demands, the machine control technology, the optimization of machining conditions and the development of finer electrode have been enhanced in wire EDM. When fine precise machining with thin wire is needed, tungsten wire has been generally used since higher wire tension for reducing the wire vibration can be loaded to the wire during machining. However, tungsten is very expensive, which leads to higher cost of product. Some kinds of coated wire has already been introduced into the market for the cost reduction, but the effects of kind of coating material and its thickness on the wire EDM characteristics have not yet been made clear sufficiently. The steel wire used as a core might be possible to strengthen.

The purpose of this study is to develop a new type of wire electrode, in which a piano wire with extremely high tensile strength is coated with electrically conductive brass layer, in order to attain high precision and high speed wire EDM. In our previous studies using the wire of $200 \mu \mathrm{m}$ in diameter, the fundamental effects of the thickness of brass and zinc layers on the machining characteristics were already made clear $^{1,2)}$. Also, using a trial-made thin wire of $50 \mu \mathrm{m}$ in diameter, the optimum thickness, quality of brass layer, the influence of the tensile strength of piano wire used as a core wire were experimentally investigated, and higher performance fine wire EDM could be attained using the optimized coated wire ${ }^{3), 4)}$.

In this paper, the surface profile of wire, particularly the surface roughness is focused and the effects of the wire surface roughness on the machining characteristics are investigated for the purpose of further improvement of wire EDM performance. In addition, sparks generated in the working gap during the process are recorded by using a high-speed video camera and the location of spark in recorded images are calculated by image analysis ${ }^{5}$. Thus, variations of spark location with time are investigated to evaluate the difference of spark location distribution with the surface roughness of wire electrode. Furthermore, electric field analysis in the gap between wire electrode and machined surface is carried out when open gap voltage is loaded, and the effect of the wire surface roughness is discussed from the viewpoint of electric intensity on the workpiece surface ${ }^{6}$.

\section{EXPERIMENTAL PROCEDURES}

\subsection{Rough surface wire electrodes}

Three type of brass wire electrode of $200 \mu \mathrm{m}$ in diameter are compared, (a) normal wire with smooth surface (commercial one), (b) small roughness wire and (c) large roughness wire. Fig.1 shows optical 


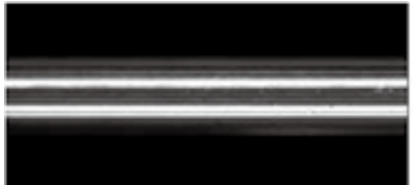

(a) Normal

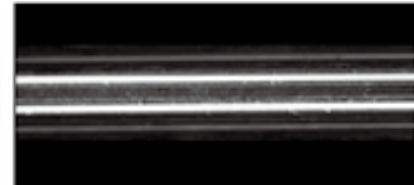

(b) Small roughness

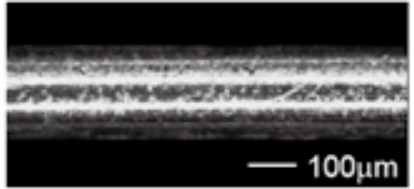

(c) Large roughness

Fig.1 Optical images of wire electrodes

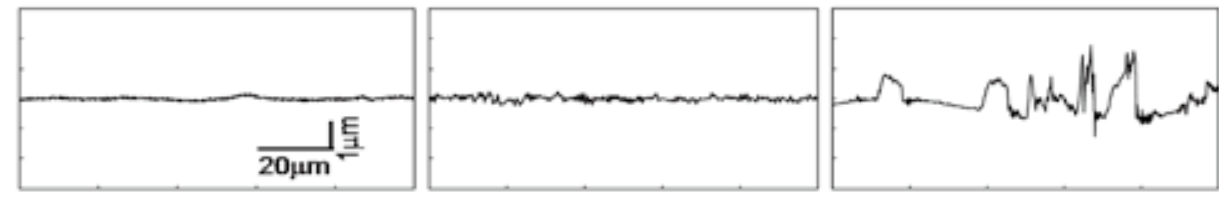

(a) Normal

(b) Small roughness

(c) Large roughness

Fig.2 Surface profiles of wire electrode

photos of them. Also the surface profiles measured by profilometer are shown in Fig.2. As shown in the figure, the surface roughness of the large roughness wire is about $3 \mu \mathrm{mRz}$. Those of the normal and small surface roughness ones are about $0.5 \mu \mathrm{mRz}$ but the frequencies are much different each other.

In this study, several manufacturing methods of wires were tried for the purpose of maintaining the mechanical and electric properties of wire, because they have to be almost the same for discussing only the effects of wire surface roughness on wire EDM characteristics. As a result, these wires were made by feeding the wire with rollers, in which small alumina abrasives are supplied between the wire and rollers. The surface roughness can be controlled mainly by the size of the abrasives used in the manufacturing process. Also it was confirmed that the abrasives hardly remain on the wire surface. Table 1 shows the mechanical and electric properties of three kinds of wire. It is obvious that there are no large differences in tensile strength, elongation and electrical conductivity between them. Therefore, the effect of only the surface roughness of wire surface on the machining characteristics can be discussed.

\subsection{Machining conditions}

Experiments were carried out using a commercial wire EDM with linear motor drive (Sodick AP200L). Workpiece material was metal mold steel SKD11 in JIS specifications, and the chemical composition is shown in Table 2. Kerosene type fluid (SodickHighTech VITOL-2) was used as working fluid. The machining characteristics, such as cutting speed, kerf width and surface roughness were investigated when the straight kerf of $10 \mathrm{~mm}$ in length was machined into SKD11 plates of $2 \mathrm{~mm}$ or $10 \mathrm{~mm}$ in thickness.

Machining condition was set to a typical 1 st cut conditions. Fig.3 shows the waveform of electrical
Table 1 Mechanical and electrical property of wire

\begin{tabular}{c|c|c|c}
\hline & Normal & $\begin{array}{c}\text { Small } \\
\text { roughness }\end{array}$ & $\begin{array}{c}\text { Large } \\
\text { roughness }\end{array}$ \\
\hline Tensile strength [MPa] & 1,021 & 1,015 & 1,025 \\
\hline Elongation [\%] & 1.6 & 1.8 & 1.7 \\
\hline $\begin{array}{c}\text { Electrical conductivity } \\
\text { [\%IACS] }\end{array}$ & 21.18 & 21.26 & 21.21 \\
\hline
\end{tabular}

Table 2 Chemical composition of SKD11

\begin{tabular}{c|c|c|c|c|c|c}
\hline $\mathrm{C}$ & $\mathrm{Si}$ & $\mathrm{V}$ & $\mathrm{Cr}$ & $\mathrm{Mn}$ & $\mathrm{Mo}$ & $\mathrm{Fe}$ \\
\hline 1.45 & 0.24 & 0.24 & 11.95 & 0.40 & 0.83 & Bal. \\
\hline
\end{tabular}

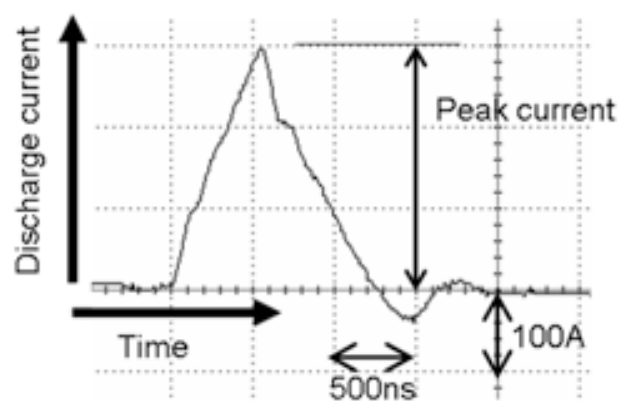

Fig.3 Electrical discharge current waveform

discharge current under this machining condition. The peak current is about $300 \mathrm{~A}$, and the pulse duration is as short as about $1 \mu$ s. Wire feeding was done by servo feeding.

\section{EFFECT OF WIRE SURFACE ROUGHNESS}

Fig.4 shows removal rates using normal wire, small roughness one and large roughness one when 


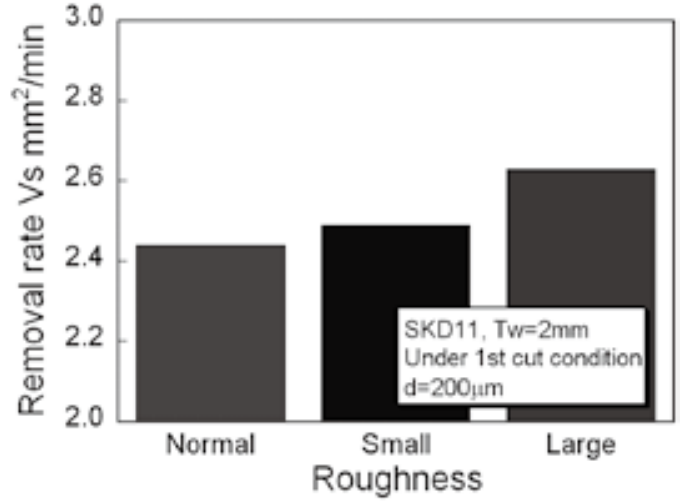

(a) $\mathrm{t}=2 \mathrm{~mm}$

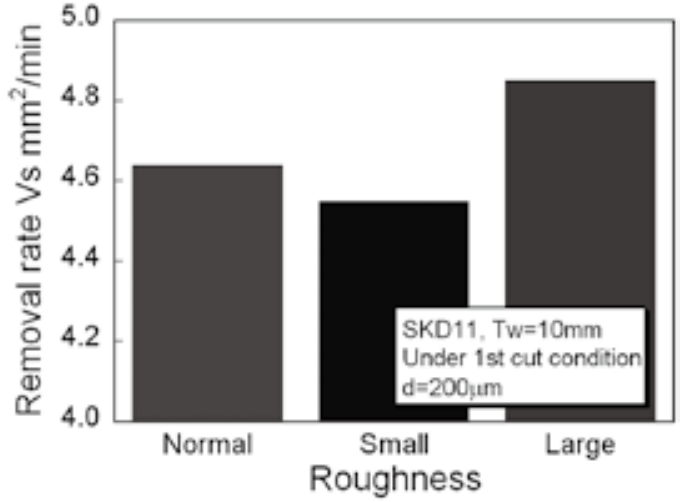

(b) $\mathrm{t}=10 \mathrm{~mm}$

Fig.4 Difference in removal rate

the workpiece thickness are (a) $2 \mathrm{~mm}$ and (b) $10 \mathrm{~mm}$. As can be seen from the figure, the removal rate using the large roughness wire is highest and those using the normal wire and the small roughness one are almost the same each other in both cases of workpiece thickness.

The gap voltage waveforms were measured in order to clarify the reason why the removal rate using the large roughness wire became higher. Typical waveforms when the workpiece thickness is $10 \mathrm{~mm}$ are shown in Fig.5. In the case of large roughness wire, the discharge frequency is higher and the delay time for sparking is shorter, compared with those in the cases of normal wire and small roughness one. When the actual discharge frequency was measured, that was about 14,200sparks/sec for normal wire, about 14,700 sparks/sec for small roughness wire, and about 15,500sparks/sec for large roughness one. These results agree well with the variation of the removal rate with wire type shown above. Therefore it is considered that the increase in discharge frequency is one of the reasons for higher removal rate using the larger roughness wire.

Fig.6 shows the difference in machined kerf width. In any kinds of wire, the kerf width is about $250 \mu \mathrm{m}$. So, the gap distance between the wire and machined surface is about $25 \mu \mathrm{m}$ because the wire diameter is $200 \mu \mathrm{m}$. The kerf width in the cases of small roughness wire and large roughness one is slightly smaller than that in the case of normal wire.

Fig.7 shows the surface roughness of machined surface inside the kerf. The increase of machined surface roughness by the large roughness wire was first expected. However, the surface roughness of machined surface did not change at all with the kind of wire.

\section{DISTRIBUTION OF SPARK LOCATION}

Improvement in removal rate by using large roughness wire was confirmed above. It was reported

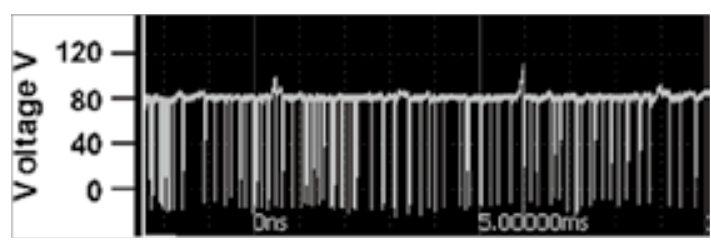

(a) Normal

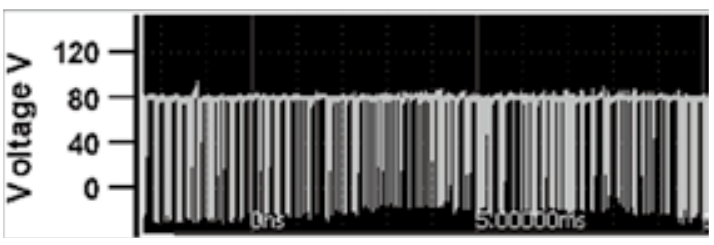

(b) Small roughness

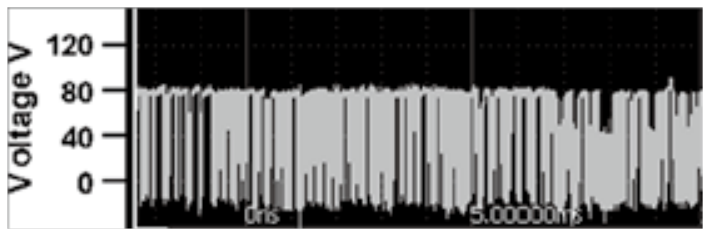

(c) Large roughness

Fig.5 Waveforms of gap voltage

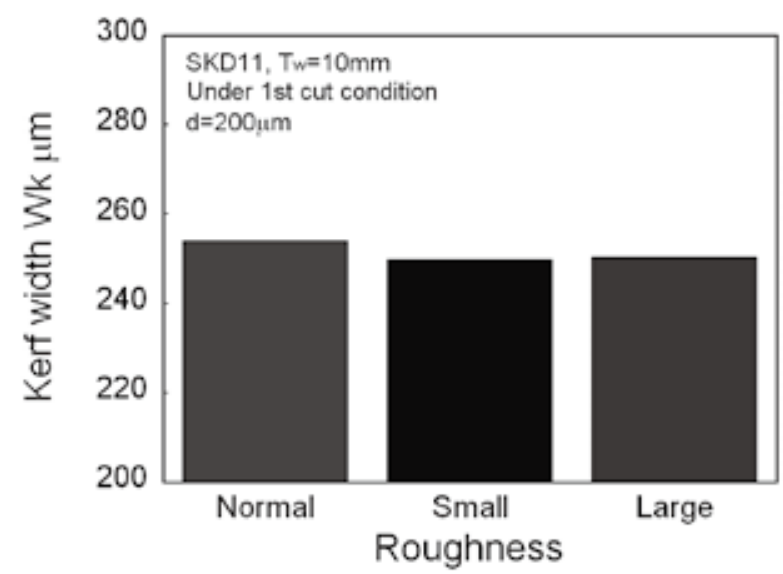

Fig.6 Difference in width of machined kerf 


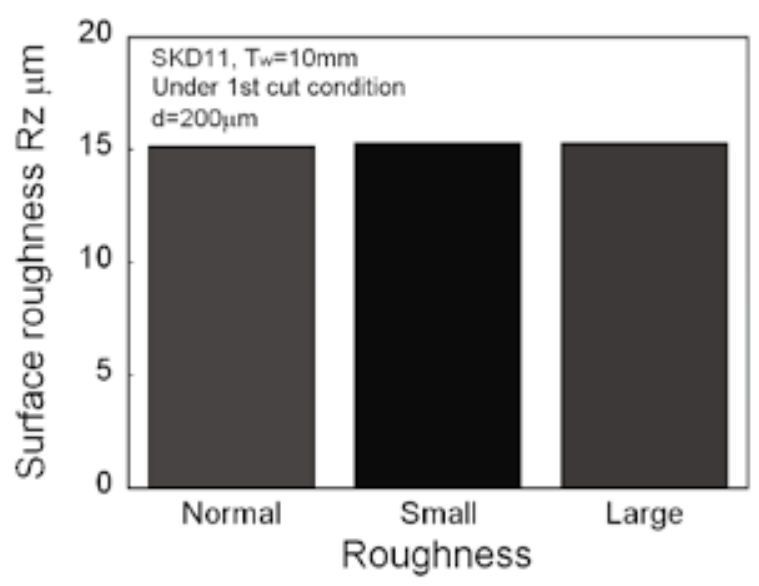

Fig.7 Difference in surface roughness

that optimum surface roughness on machined surface or electrode surface leads to uniform distribution of spark locations. The increase of removal rate with using large roughness wire might be caused by uniform distribution of spark location. Then, the distribution of spark location was evaluated here.

The position of spark location was directly detected by using a high-speed video camera (KEYENCE VW-6000). As shown in Fig.8, the observation system consists of a running wire, a workpiece, and a small working tank made of acrylic resin. Fig.9 shows the observed area of sparks in wire EDM. The view size is $13.2 \times 12.4 \mathrm{~mm}$, which covers the workpiece thickness of $10 \mathrm{~mm}$. The sparks were observed from the rear side of wire by a digital high-speed video camera. The recording rate was 4,000 frames per second. In order to catch clearly the sparks in the image analysis process, the recording was carried out without any illuminations. The recording was started after the kerf of $0.5 \mathrm{~mm}$ in length was machined.

A commercial image analysis software (DITECT DIPP-Macro) was used for the analysis of recorded images with high-speed video camera. Fig.10 shows the schematic arrangement of wire and workpiece(a), high-speed observation image of spark (b), and image analyzed result (c). As can be seen from (b), the original image of spark recorded by high-speed video camera is not so clear, but the image was sharpened and binarized into white and black by the image analysis software (c). Then, y position of center of the spark was calculated. The image analysis was done in this manner for all images in the high-speed observation.

Fig.11 shows the distance of spark position from lower edge of workpiece using three kinds of wire electrode. In the case of normal wire, sparks somewhat concentrate at upper part in the first half of the recording time. On the other hand, they concentrate at lower part in the second half. That is,

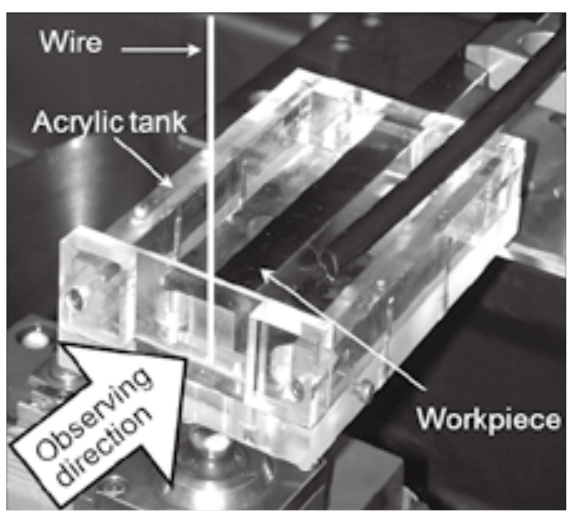

Fig.8 Overview of high-speed observation model

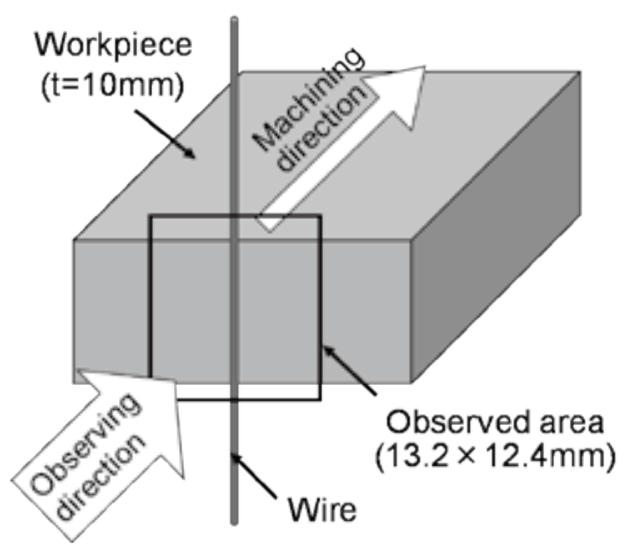

Fig.9 Observed area

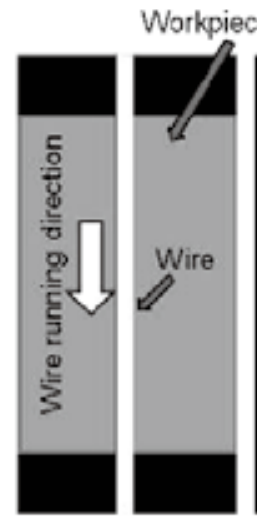

(a)

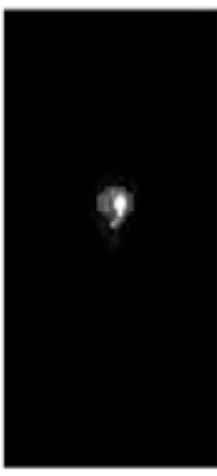

(b)

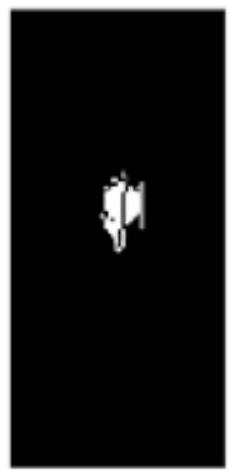

(c)
Fig.10 Recorded and processed image

spark concentration area moves from top to bottom in the case of normal wire. In the cases of small and large roughness wire, spark concentration area does not obviously appear, which indicates that spark location can be uniformly distributed by using surface roughened wire. Particularly in the case of large roughness wire, the distribution of spark location is fairly uniform as shown in (c). 


\section{ELECTRIC FIELD ANALYSIS}

An electrical discharge starts by electron emission from cathode surface, and the ease of discharge generation is directly influenced by electric field intensity at discharging point just before discharge starts. The electric field in the gap between wire and machined surface was discussed by electric field analysis.

In order to obtain the electric field intensity for electron emission from brass wire surface, single pulse discharge experiment was carried out. As shown in Fig.12, the tip of electrode is coned, in which the tip angle is about $60^{\circ}$. The gap distance was measured when electrical discharge occurred between SKD11 electrode $(+)$ and brass plate workpiece (-). The gap distance was measured ten times, and the average gap distance was $31 \mu \mathrm{m}$.

Next, electric field just before the electrical discharge occurs in the single pulse discharge experiment was analyzed, and the electric field intensity needed for discharge generation was calculated $^{6)}$. Static electric field analysis was done using commercial FEM software (TriComp Estat6.0). The shapes of electrode and workpiece in the analysis model are the same as those in the single pulse discharge experiment, and the relative permittivity of kerosene type machining fluid between the electrode and the workpiece was set to 2.0. The gap distance was set to $31 \mu \mathrm{m}$, which was obtained in the single pulse discharge experiment. Fig.13 shows the analyzed equilibrium potential lines in the gap when open voltage is loaded. From this result, the maximum electric field intensity on brass electrode surface was calculated and it was $3.87 \times 10^{6} \mathrm{~V} / \mathrm{m}$. In other words, it was made clear that the electric field intensity needed for electron emission from the brass electrode surface into kerosene type working fluid and discharge occurrence $E_{\mathrm{s}}$ is $3.87 \times 10^{6} \mathrm{~V} / \mathrm{m}$.

Fig.14 shows the analyzed static electric field in the gap between the electrode and machined surface when large roughness wire electrode. In this analysis, actual surface profiles of wire electrode and machined surface of workpiece were measured, and they are given to the analysis model. The potential between the electrode and the workpiece was open voltage of $80 \mathrm{~V}$, and the gap distance was calculated by the kerf width and the diameter of wire after machining.

Then, the distribution of electric field intensity on the wire electrode surface was calculated. Fig.15 shows the results in the cases of normal wire, small roughness wire and large roughness wire. As a matter of course, equilibrium potential line becomes dense and the electric field intensity increases on the convex parts of wire surface. Es in the graph is the threshold needed for discharge occurrence, obtained by the

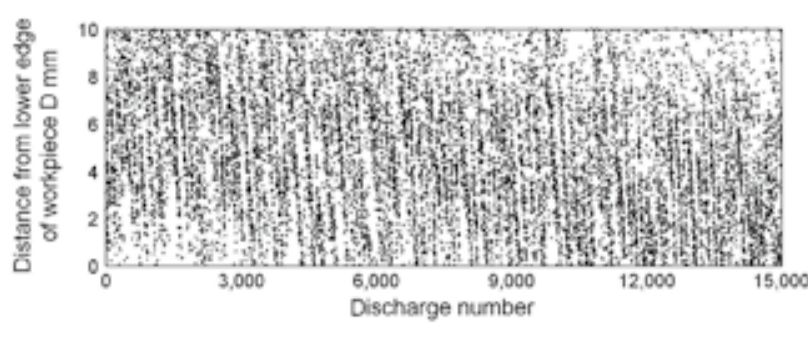

(a) Normal

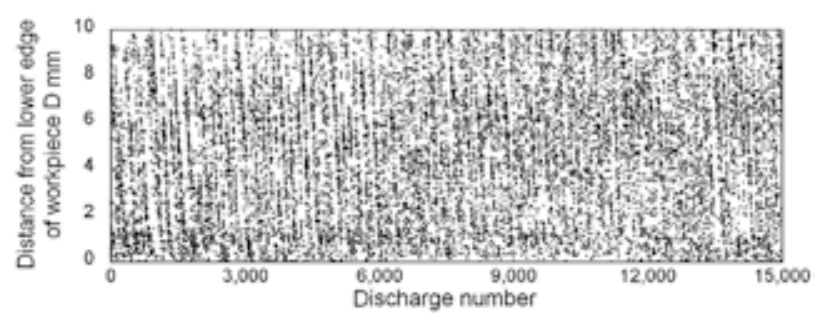

(b) Small roughness

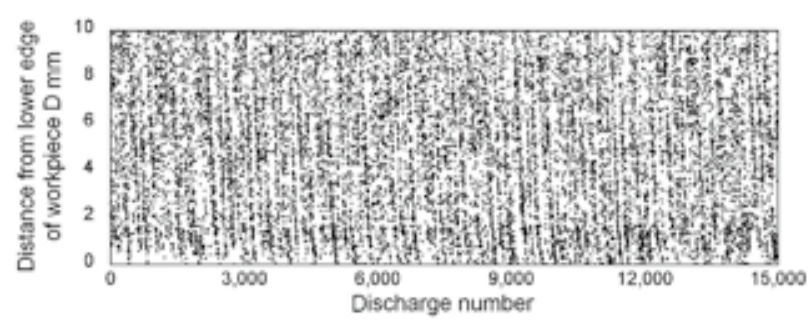

(c) Large roughness

Fig.11 Distribution of discharge location

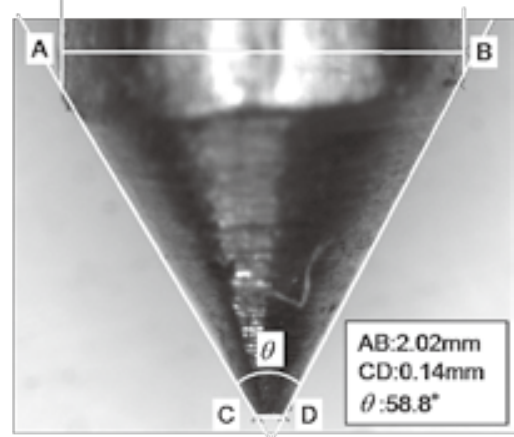

Fig.12 Dimensions of electrode used in a single pulse discharge experiment

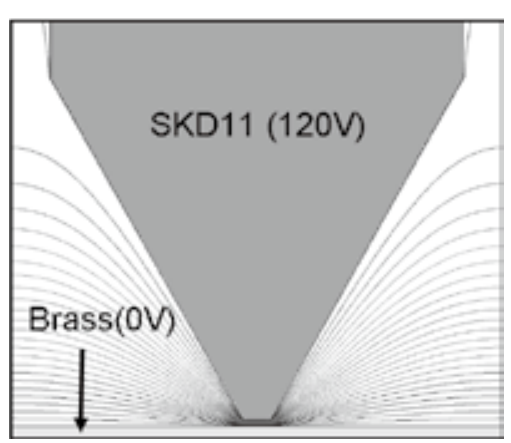

Fig.13 Electric field in a single pulse discharge 


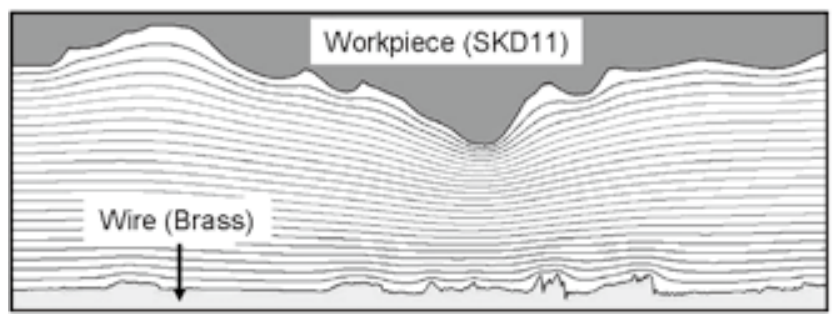

Fig.14 Electric field between wire electrode and machined surface

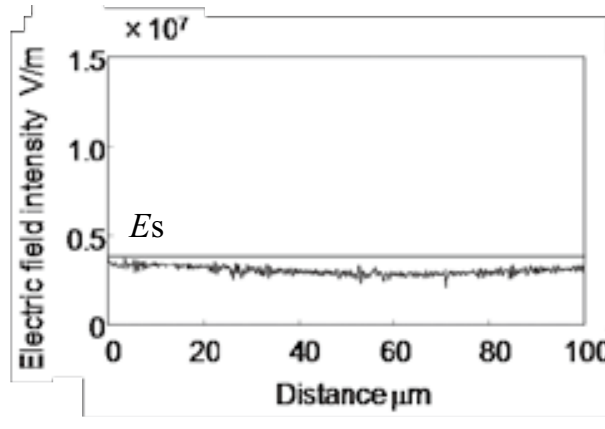

(a) Normal

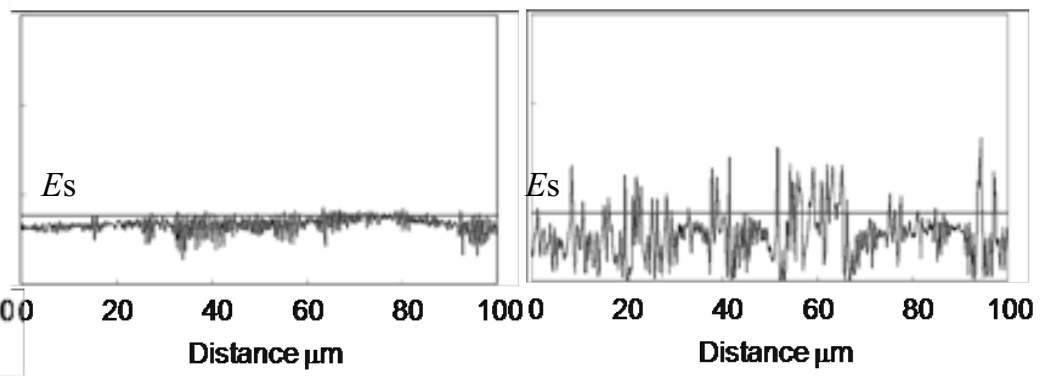

(c) Large roughness

Fig.15 Electric field intensity distributions of wire surface

single pulse discharge and its electric filed analysis. As can be seen from the figure, the electric field intensity varies significantly in the case of large roughness wire. And the electric filed intensity is beyond the threshold at many positions. On the other hand, there are a few positions in the case of normal wire. Therefore, it can be understood that large roughness wire has a surface profile in which discharge is very easy to occur. The occurrence of discharge is probabilistic phenomenon ${ }^{7), 8}$. So, even on the position with low electric field intensity less than $E$ s, discharge may occur. However, judging from high discharge frequency with large roughness wire shown above, the increase of removal rate in the case of large roughness wire is caused by its many positions on the wire surface with high electric field intensity.

\section{CONCLUSIONS}

(1) The removal rate in wire EDM using the wire with optimum surface roughness is larger than that using normal wire, regardless of workpiece thickness.

(2) The discharge frequency becomes high and the distribution of discharge location becomes uniform when the wire with optimum surface roughness is used.

(3) The width and the surface roughness of machined kerf using the wire with optimum surface roughness are almost the same as those using normal wire.

(4) The electric field intensity needed for electron emission from the brass cathode electrode surface into kerosene type working fluid is about $3.9 \times 10^{6} \mathrm{~V} / \mathrm{m}$.

(5) On the wire surface with optimum surface roughness for higher removal rate, there are many positions with electric field intensity higher than the electric field intensity needed for electron emission.

\section{ACKNOLEDGEMENTS}

The authors would like to express their thanks to Sodick Co., Ltd. for their help. A part of this study was financially supported by Osawa Scientific Studies Grants Foundation and Mazak Foundation.

\section{REFERENCES}

1) M. Morita, T. Yamauchi, A. Okada, Y. Uno and T. Shimizu: Fundamental Study on Coating Wire Electrode for High Performance WEDM, Proc. of the 3rd International Conference on Leading Edge Manufacturing in 21st Century, (2005) 779-782.

2) T. Yamauchi, A. Okada, M. Morita, T. Shimizu and Y. Uno: Development of Coat Wire Electrode for High Performance WEDM $\left(1^{\text {st }}\right.$ report), J. of JSEME, Vol.39 No.92 (2005) 28-35 (in Japanese).

3) A. Okada, T. Yamauchi, K. Arizono, T. Shimizu and Y. Uno: Development of Coat Wire Electrode for High Performance WEDM $\left(2^{\text {nd }}\right.$ 
report), J. of JSEME, Vol.42 No.99 (2008) 12-19 (in Japanese).

4) A. Okada, T. Yamauchi, K. Arizono, and Y. Uno: Effect of Surface Quality of Brass Coating Wire on Wire EDM Characteristics, J. of Advanced Mechanical Design System and Manufacturing, Vol.2, No.4, (2008) 735-741.

5) A. Okada, Y. Uno, M. Nakazawa and $T$. Yamauchi: Evaluations of Spark Distribution and Wire Vibration in Wire EDM by High-speed Observation, CIRP Annals Manufacturing Technology, Vol.59, No.1 (2010) 231-234.
6) I. Araie, S.Sano and M. Kunieda: Influence of Electrode Surface Profile on Discharge Delay Time in Electrical Discharge Machining, IJEM, No.13, (2008), 21-27.

7) M. Kunieda and T. Nakashima: Factors Determining Discharge Location in EDM, IJEM, No.3, (1998) 53-58.

8) K. Morimoto and M. Kunieda: Sinking EDM Simulation by Determining Discharge Location Based on Discharge Delay Time, CIRP Annals Manufacturing Technology, Vol.59, No.1 (2009) 221-224. 